\section{Toxicity of lead at low dose}

SIR,-A recent editorial (1989;46:5936) reviewed the "low dose" toxicity of lead including any "...neurological damage to the fetus at blood lead concentrations as low as 15-20 $\mu \mathrm{g} / \mathrm{dl}$..."; reference was made to two American and to one Australian prospective studies. ${ }^{1-3}$

Children aged 4 who lived in a South Australian lead smelting city (population 15000) and whose average postnatal blood lead concentration was $31.05 \mu \mathrm{g} / \mathrm{dl}$ “...had a general cognitive score $7 \cdot 2$ points lower... than those with an average concentration of $10.35 \mu \mathrm{g} / \mathrm{dl}$...", Neverthleless, McMichael et al referred to the need to be "circumspect in making causal influences from studies of this relation...."3

Parallel findings were not obtained in a study of similar aged children who lived in Sydney, Australia, which has a population of $2.5 \mathrm{~m}$. From an initial cohort of 218 children, 207 remained in the study at the end of the fourth year; their average blood lead concentration at that time was $10 \cdot 1 \mu \mathrm{g} / \mathrm{dl}$ with only a few observations exceeding 15 $\mu \mathrm{g} / \mathrm{dl}$. The regression analyses showed that concentrations in the range of $10 \cdot 1$ to $10.7 \mu \mathrm{g} / \mathrm{dl}$ were not associated with mental or motor deficits ${ }^{4}$ as assessed by the McCarthy scales. ${ }^{5}$

Similarly, neither of the regressions using a weighted combination of previous and current blood lead concentrations as the independent variable (which represents the total exposure to lead over the four years) yielded a significant relation. ${ }^{4}$

Statistical analyses have also been carried out on children aged $3^{6}$ and at 5
(GH Cooney, A Bell. Environmental toxicology group of the Victorian branch of the Royal Australian Chemical Institute and the Australian and New Zealand Environmental Mutagens Society, Ballarat, Victoria, 1988): the former did not support the hypothesis of a relation between Sydney maternal and cord blood lead concentrations up to $29 \mu \mathrm{g} / \mathrm{dl}$ and developmental deficits. ${ }^{6}$ At age 5, there were no significant mental deficits associated with cord blood lead concentrations about $10 \mu \mathrm{g} / \mathrm{dl}$ (Cooney and Bell), as have been reported in America. ${ }^{2}$ Both Australian studies are proceeding and the children, now aged 7 , are being assessed.

A BELL 12 Beatrice Street, Clontarf, NSW 2093, Sydney, Australia

1 Bornschein RL, Hammond PB, Dietrich KN, et al. The Cincinnati prospective study of low-level lead exposure and its effects on child development protocol and status report. Environ Res 1985;38:4-18.

2 Bellinger D, Leviton A, Watermaux C, Needleman H, Rabinowitz M. Longitudinal analysis of prenatal and post-natal exposure and early cognitive development. $N$ Engl J Med 1987;317:1037-43.

3 McMichael AJ, Baghurst PA, Wigg NR, Vimpani GV, Robertson EF. Port Pirie cohort study: environmental exposure to lead and children's ability at age of four years. $N$ Engl J Med 1988;319:468-75.

4 Cooney GH, Bell A, Carter C, McBride W. Low level exposures to lead: the Sydney lead study. Dev Med Child Neurol 1989;31:640-9.

5 McCarthy D. Manual for the McCarthy scales of children's abilities. New York: Psychological Corporation, 1972.
6 Cooney GH, Bell A, McBride W, Carter. C. Neurobehavioural consequences o prenatal low level exposures to leads Neurotoxicol Teratol 1989;11:95-114

Tenth annual epidemiology sum mer programme, Tufts Univer $\Phi$ sity, Medford, Massachusetts, 15 July-3 August 1990

The New England Epidemiology In stitute and Tufts University will spon sor a three week summer programme in epidemiology at Tufts' Medfor campus. The programme includesboth methodological and substantive courses. Fourteen courses will be offered, including theory and practiceof epidemiology (introductory an advanced levels), causal inference, biostatistics for epidemiologists regression and categorical data meth ods, logistic regression and surviva analysis, conducting epidemiologiğ research, biology and epidemiology of cancer, environmental epidemiology? occupational epidemiology, statisticaf inference, nutritional epidemiology clinical epidemiology, and ecologicat analysis. Registrants may receive graduate degree credit, continuing medical education credit (AMAD category 1) through the Postgraduate Medical Institute or certification maintenance credits in industria?. hygiene. For more information please contact: New England Epidemiolog它 Institute, Dept SC-7, 826 Boylston Sto Chestnut Hill, MA 02167, USA. 